Cadernos de Estudos Sociais e Políticos, Rio de Janeiro, vol. 6, 2018.

\title{
O Movimento Brasil Livre E O Ativismo Online De Inspiração Liberal/Conservadora
}

\author{
The Brasil Livre Movement And The Online Activism Of Liberal/Conservative Inspiration
}

Renan Alfenas de Mattos ${ }^{1}$

\section{RESUMO}

O Movimento Brasil Livre, cuja origem remete às Jornadas de Junho de 2013, teve importância recente no país ao ajudar a convocar protestos a favor do impeachment de Dilma Rousseff, a partir, principalmente, das mídias sociais da Internet. Ao investigarmos as origens do MBL, notamos conexões com uma rede global de think tanks orientados pela defesa do liberalismo econômico. Já quando analisamos suas performances, notamos um discurso anticorrupção tendo como foco o antipetismo, aliado a influências de um discurso liberal na economia e conservador nos costumes. Sendo assim, o objetivo do estudo é refletir sobre o ativismo de inspiração liberal/conservadora do MBL. Pretende-se analisar o surgimento do movimento, bem como sua forma de atuação, por meio da análise de postagens no YouTube, levando-se em conta o contexto dos protestos pró-impeachment e do surgimento de uma nova direita no Brasil.

PALAVRAS-CHAVE: Movimento Brasil Livre; ativismo online; think tanks; frame analysis; nova direita.

\begin{abstract}
The Movimento Brasil Livre, whose origin goes back to the Jornadas de Junho de 2013, had recent importance in the country by helping to call for protests in favor of the impeachment of Dilma Rousseff, mainly from the social media of the Internet. When we investigate the origins of the MBL, we note connections to a global network of think tanks guided by the defense of economic liberalism. When we analyze their performances, we note an anti-corruption discourse focusing on antipetism, combined with influences from a liberal discourse in the economy and conservative in customs. Therefore, the aim of the study is to analyze MBL's liberal / conservative activism. It is intended to analyze the emergence of the movement, as well as its form of action, through the analysis of posts on YouTube, considering the context of the pro-impeachment protests and the emergence of a new right in Brazil.
\end{abstract}

KEYWORDS: Movimento Brasil Livre; online activism; think tanks; frame analysis; new right.

1 Doutorando no Programa de Pós-graduação em Sociologia da Universidade Federal Fluminense. Pesquisador do Laboratório de Sociologia Digital - PPGS - UFF, e do grupo de pesquisa Discurso, redes sociais e identidades sóciopolíticas (DISCURSO) - CPDA - UFRRJ. E-mail: ramattos7@gmail.com. 
Cadernos de Estudos Sociais e Políticos, Rio de Janeiro, vol. 6, 2018.

\section{INTRODUÇÃO}

Em vídeo publicado no dia 15 de abril de 2018, na página do MBL no Facebook, lê-se: "Flávio Rocha diz que Brasil precisa de um Ronald Reagan ou uma Thatcher", além da legenda: “Nós não precisamos de um fenômeno Macron!”. Flávio, o proprietário da rede de lojas Riachuelo, foi pré-candidato à Presidência da República pelo PRB em 2018, mas acabou desistindo do pleito. No mesmo vídeo, explica que se coloca com uma opção de candidatura de direita na economia e nos costumes, inspirado no ex-presidente norte-americano Ronald Reagan (1981-1989) e na exprimeira-ministra britânica Margareth Thatcher (1979 - 1990); ao mesmo tempo, se diferencia de Emmanuel Macron, atual presidente da França, que seria um político de direita na economia e esquerda nos costumes. Em artigo de opinião publicado na Folha de $\mathrm{SP}^{2}$, Kim Kataguiri, uns dos coordenadores do MBL, declarou que Flávio Rocha seria o candidato do Movimento nas eleições presidenciais de 2018. Porém, Flávio acabou desistindo da disputa ${ }^{3}$.

O exemplo do vídeo acima busca elucidar algumas das influências do movimento, enquanto apresenta o foco de análise empírica: os vídeos postados no YouTube.

O Movimento Brasil Livre, tendo como seus membros mais populares Kim Kataguiri, Fernando Holiday, Artur do Val, Renan Santos e Alexandre Santos, tornou-se conhecido pela participação nas manifestações a favor do Impeachment da ex-presidente Dilma Rousseff, fazendo uso maciço das mídias sociais.

Primeiramente, na história do Brasil, é raro um grupo que se auto identifica com a Direita política conseguir mobilizar protestos nas ruas com um grande número de pessoas, como ocorreu em 2015 e 2016. Esses repertórios de confronto político são historicamente ligados a grupos identificados com a Esquerda política ${ }^{4}$.

Em segundo lugar, o Movimento Brasil Livre tem como sua principal forma de mobilização o ativismo via mídias sociais. É postada uma quantidade diária gigantesca de informações em sua página oficial no Facebook, em seu canal do YouTube e em sua conta no Twitter. Isso contrasta o otimismo inicial que se enxergava nas mídias sociais. Apesar de ser um veículo importante de luta

\footnotetext{
2 Disponível em: <https://www1.folha.uol.com.br/opiniao/2018/03/kim-kataguiri-o-candidato-dombl.shtml?>. .Acesso em 21-05-2018.

3 No dia 13/07/2018, Flávio Rocha anunciou a desistência de sua candidatura presidencial. Disponível em: $<$ https://istoe.com.br/flavio-rocha-desiste-de-candidatura-a-presidencia/ >.

$4 \quad$ Assumimos que Esquerda e Direita devem ser pensadas em sentido relacional.
} 
Cadernos de Estudos Sociais e Políticos, Rio de Janeiro, vol. 6, 2018.

contra as opressões, dando voz a movimentos de gênero, raça e anticapitalistas, assim como a grupos marginalizados em todo o mundo, a Internet, como qualquer outra ferramenta tecnológica, está disponível a pessoas, grupos políticos, empresas e governos de todos os espectros políticoideológicos.

Presenciamos recentemente uma influência gigantesca da Internet, em manifestações com um discurso conservador. A filósofa Judith Butler foi alvo de uma petição online, no site CitizenGo, que chegou a reunir mais de 360 mil assinaturas pelo cancelamento da palestra que ela daria em São Paulo em novembro de 2017. Além disso, ocorreram protestos em frente ao SESC de SP, local da palestra, onde as pessoas protestavam contra a "ideologia de gênero" "Também ocorreram protestos contra as exposições artísticas do QueerMuseu ${ }^{6}$ e do $\mathrm{MAM}^{7}$.

A influência da Internet para a política conservadora não se restringiu ao Brasil. A Cambridge Analytica, por exemplo, teve um papel de destaque na eleição de Donald Trump e na campanha do Brexit, com duas vitórias que contrariaram os prognósticos iniciais. A empresa foi acusada de roubar dados pessoais do Facebook de 50 milhões de pessoas e, a partir daí, direcionar propagandas políticas e fake news para grupos de eleitores extremamente setorizados (CARDOSO, 2018).

Voltando ao Brasil: a campanha de Jair Bolsonaro, que o ajudou a vencer as Eleições presidenciais em 2018, com apenas 11 inserções de 8 segundos de campanhas na TV $^{8}$, fez uso maciço do Facebook e WhatsApp, por exemplo. Eleitores do candidato de extrema-direita foram os que mais se informaram por WhatsApp e os que mais utilizaram alguma rede social, segundo pesquisa do Instituto Datafolha?.

O MBL, que possui pautas conservadoras nos costumes e liberais na economia, também se insere nessa onda. O movimento se utiliza de diversos repertórios de ação coletiva que perpassam as dimensões online e offline, tanto para disputar a interpretação de eventos diários quanto para

\footnotetext{
5 Disponível em: https://noticias.uol.com.br/cotidiano/ultimas-noticias/2017/11/07/manifestantesprotestam-contra-filosofa-americana-judith-butler-em-sao-paulo.htm?cmpid=copiaecola.

6 "Os protestos acusam a exposição de blasfêmia a símbolos religiosos e de, em alguns casos, pedofilia e zoofilia. O MBL (Movimento Brasil Livre) é um dos grupos que engrossaram as críticas à mostra." Disponível em: <https://www1.folha.uol.com.br/ilustrada/2017/09/1917269-apos-protesto-mostra-com-tematica-lgbt-em-portoalegre-e-cancelada.shtml>.

"A performance de um artista nu no Museu de Arte Moderna (MAM), no Ibirapuera, Zona Sul de São Paulo, gerou polêmica nas redes sociais. Um vídeo que viralizou no Facebook mostra quando uma criança de aproximadamente quatro anos toca no pé do homem. O Movimento Brasil Livre (MBL) e outros movimentos de direita falam em crime; desembargador vê "histeria". Disponível em: <https://g1.globo.com/saopaulo/noticia/interacao-de-crianca-com-artista-nu-em-museu-de-sp-gera-polemica.ghtml>.

8 Disponível em: <https://veja.abril.com.br/politica/bolsonaro-tera-8-segundos-de-tempo-de-tv-alckmin5 minutos $/>$.

9 Disponível em: <https://www1.folha.uol.com.br/poder/2018/10/eleitores-de-bolsonaro-sao-os-que-maisusamas-redes-sociais.shtml $>$.
} 
Cadernos de Estudos Sociais e Políticos, Rio de Janeiro, vol. 6, 2018.

mobilizar apoiadores. Dessa forma, se as postagens nas mídias sociais são importantes para o movimento, os atos nas ruas e em outros espaços públicos também os são.

O objetivo do presente trabalho é analisar o surgimento do Movimento Brasil Livre assim como sua forma de atuação. Começaremos por investigar sua origem, que nos leva a sua relação com o think tank Atlas Network; depois refletiremos sobre seu ativismo online de acordo com resultados da análise de uma amostra de vídeos do YouTube, além dos processos de enquadramento.

\section{ORIGEM E CONEXÕES COM THINK TANKS}

Juliano Torres, um dos fundadores do Estudantes Pela Liberdade, por meio de entrevista concedida à Marina Amaral (2015), da Agência Pública, ajuda a elucidar alguns pontos que relacionam o Movimento a Atlas Network, ao EPL e a versão original, o Students For Liberty:

Quando teve os protestos em 2013 pelo Passe Livre, vários membros do Estudantes pela
Liberdade queriam participar, só que, como a gente recebe recursos de organizações
como a Atlas e a Students for Liberty, por uma questão de imposto de renda lá, eles não
podem desenvolver atividades políticas. Então a gente falou: 'Os membros do EPL
podem participar como pessoas físicas, mas não como organização para evitar problemas.
Aí a gente resolveu criar uma marca, não era uma organização, era só uma marca para a
gente se vender nas manifestações como Movimento Brasil Livre. Então juntou eu, Fábio
[Ostermann], juntou o Felipe França, que é de Recife e São Paulo, mais umas quatro,
cinco pessoas, criamos o logo, a campanha de Facebook. E aí acabaram as manifestações,
acabou o projeto. E a gente estava procurando alguém para assumir, já tinha mais de 10
mil likes na página, panfletos. E aí a gente encontrou o Kim [Kataguiri] e o Renan [Haas],
que afinal deram uma guinada incrível no movimento com as passeatas contra a Dilma e
coisas do tipo. Inclusive, o Kim é membro da EPL, então ele foi treinado pela EPL
também. E boa parte dos organizadores locais são membros do EPL. Eles atuam como
integrantes do Movimento Brasil Livre, mas foram treinados pela gente, em cursos de
liderança. O Kim, inclusive, vai participar agora de um torneio de pôquer filantrópico
que o Students For Liberty organiza em Nova York para arrecadar recursos. Ele vai ser
um palestrante. E também na conferência internacional em fevereiro, ele vai ser
palestrante.

Notamos que, na página do Facebook do MBL, a fundação do Movimento é indicada como ocorrida em 1 de novembro de 2014. O que nos leva a crer que, baseado na entrevista, esse foi o momento em que Kim e Renan assumem a página, que já existia desde 2013.

Mas o que a Atlas, o Students for Liberty e o Estudantes pela Liberdade têm em comum? Os três são organizações conhecidas como think tanks. 
Cadernos de Estudos Sociais e Políticos, Rio de Janeiro, vol. 6, 2018.

Para Denise Gros, (2008, p.3), os think tanks são institutos privados de pesquisa presentes no processo de formulação de políticas públicas orientadas pela doutrina do liberalismo, por meio da produção de conhecimento sobre temas sujeitos à regulamentação pública. Cabe destacar que tais institutos financiam suas atividades, que incluem publicações e debates realizados por equipes técnicas de alto nível, por meio de doações de grandes empresas. Tais redes de think tanks, existentes nos EUA e Inglaterra desde os anos 40, contribuíram com críticas ao Estado de Bem-estar Social, que embasaram a atuação política de líderes como Ronald Reagan e Margaret Thatcher. A autora (Ibid, p.4) também atenta para a importância de tais redes para a consolidação do neoliberalismo e para a internacionalização do movimento neoliberal nos anos 80 .

Segundo o sociólogo Timothy Mitchell (2015), o mundo das ideias no período pós-Segunda Guerra Mundial era inóspito ao individualismo radical, que é a base de um liberalismo econômico acentuado, também chamado de ultraliberalismo ${ }^{10}$. O economista Friedrich August Von Hayek foi um dos principais nomes responsáveis pela expansão dessas ideias ultraliberais, bem como para a organização política dos think tanks. Para ele, os "intelectuais", que seriam pensadores de "segundo nível", como jornalistas, professores, comentadores de mídia, cineastas, escritores de ficção, entre outros, se diferenciariam do "erudito ou especialista em um campo particular". Os intelectuais controlariam a distribuição de conhecimento especializado para os membros da população e atuariam como "second-hand dealers of ideas", ou vendedores de segunda mão de ideias. Dessa forma, um movimento neoliberal deveria alterar as ideias distribuídas entre os vendedores de segunda mão, para assim, alterar o "clima de opinião" no mundo. Era também importante que houvesse um líder, um "empreendedor intelectual” que "energizaria a equipe de vendas e seria seu porta voz" (Ibid., p. 386-387).

A obra seminal de Hayek, "O caminho da servidão", foi uma das principais do movimento de expansão neoliberal no campo das ideias. Nela, o autor critica o keynesianismo, destacando que as medidas econômicas advindas do modelo, um caminho do meio entre um sistema democrático que privilegiasse a defesa da propriedade privada individual e um sistema autoritário no qual as propriedades seriam coletivas, levaria, no longo prazo, a este modelo (GROS, 2008). Logo, o Estado de Bem-Estar Social era propenso a falhar, para Hayek. Segundo Camila Rocha (2017, p.99):

Nesta obra, Hayek, fundador da Sociedade de Mont Pelerin, amigo de longa data de John Maynard Keynes, e ex-aluno de Ludwig von Mises, o mais importante nome da escola austríaca de economia, argumenta que o aprofundamento da lógica "coletivista" e

10 Para Baggio (2016, p.1), o termo ultraliberal é mais preciso que o neoliberalismo, pois "pois sintetiza as propostas de um liberalismo acentuado, na era da globalização financeira”. 
Cadernos de Estudos Sociais e Políticos, Rio de Janeiro, vol. 6, 2018.

"estatista" que ampararia o Estado de Bem-estar Social conduziria ao totalitarismo e,
portanto, ao fim das liberdades individuais.

Em 1947, em Mont Pèlerin, na Suíça foi realizada uma conferência internacional de 10 dias onde o liberalismo foi debatido com vários nomes importantes ${ }^{11}$ para o movimento (GROS, 2008). Ao final da conferência, foi criada a Sociedade Mont Pelèrin, importante para a organização do movimento neoliberal já que entre seus integrantes estão vários criadores de think tanks ${ }^{12}$ pelo mundo (MITCHELL, 2008). Outras organizações importantes dessa época para o movimento foram a Fundation for Economic Education, criada em 1946 e a Escola de Economia de Chicago.

O Institute of Economic Affairs (IEA), criado em 1955 por Anthony Fisher, teve grande importância para os governos de Margareth Thatcher como primeira-ministra (1979-1990) e Ronald Reagan como presidente (1981-89). Segundo o economista Milton Friedman (que teve sua doutrina monetarista importada pelo IEA nos seus materiais), citado pelo jornalista Lee Fang (2016):

O IEA, fundado por Antony Fisher, fez toda a diferença, disse Milton Friedman uma vez. "Ele possibilitou o governo de Margaret Thatcher - não a sua eleição como primeiraministra, e sim as políticas postas em prática por ela. Da mesma forma, o desenvolvimento desse tipo de pensamento nos EUA possibilitou a implementação das políticas de Ronald Reagan, afirmou.

No caso de Thatcher, o IEA, localizado na Inglaterra, fomentou os debates a favor do livremercado desde a década de 1950, ajudando a tornar o liberalismo a ideologia dominante com a ajuda dos meios de comunicação e da formação de uma geração de intelectuais. Ela também se utilizou do IEA para aprofundar seus conhecimentos sobre teoria monetarista, encontrando-se com Hayek, em 1975, e com Milton Friedman, em 1978, através do think tank (GROS, 2008). Dessa forma, muitas políticas da primeira-ministra de cunho liberalizante foram embasadas ideologicamente nos estudos da IEA, que inclusive ofereceu quadros e assessores técnicos para o governo (ROCHA, 2017, p.100).

11 Os participantes da reunião em Mont Pelerin eram economistas europeus e norte-americanos conhecidos e que desempenhariam papel importante na divulgação do liberalismo em seus países. A Escola Austríaca de Economia estava representada por Friederich Hayek e Ludwig Von Mises. Da Inglaterra, vieram Lionel Robbins e Stanley Deninson, da London School of Economics; John Jewkes, da Universidade de Oxford; Michael Polanyi, da Universidade de Manchester; e o Jornalista e Historiador C. V. Wedgewood. A Alemanha estava representada por Willian Röpke e Walter Eucken, da Escola de Freiburg. Dos EUA, vieram o Jornalista Henry Hazlitt, do New York Times e da Newsweek; os Economistas Leonard Read, F. A. Harper e V. O. Watts, da Foundation for Economic Education; e os professores da Universidade de Chicago Frank Knight, Aaron Director, George Stigler e o jovem Milton Friedman. Os liberais franceses enviaram Jacques Rueff, titular do Tesouro francês no entre-guerras, o Professor de Economia Maurice Allais e o Jornalista Bertrand de Jouvenel. Outros presentes eram o Professor Willian Rappart, do Institut Universitaire des Hautes Études Internationales de Genéve, além de representantes da Itália e da Noruega (COCKETT, 1995 apud GROS, 2008).

12 Outras instituições importantes dessa época para o movimento neoliberal foram a Fundation for Economic Education, criada em 1946 e a Escola de Economia de Chicago(Mitchell, 2008). 
Cadernos de Estudos Sociais e Políticos, Rio de Janeiro, vol. 6, 2018.

O mesmo Anthony Fisher da IEA criou, em 1981, com o apoio ${ }^{13}$ de Hayek, Thatcher e Friedman, a Atlas Economic Research Foundation, que depois mudou de nome para Atlas Network, com a ideia de que fosse uma "organização-mãe" que coordenasse os think tanks já criados e apoiasse novas “filiais" em outros países (ROCHA, 2017, p. 101). No mesmo ano de 1981, iniciava nos EUA o governo de Ronald Reagan, com pautas liberal-conservadoras, "caracterizado pela defesa do livre mercado, desregulamentação da economia, cortes de impostos e redução do orçamento de programas sociais", além da retomada da corrida armamentista e do discurso anticomunista. (BAGGIO, 2016, p.2)

Em 2013, o nome da organização foi alterado para Atlas Network. Atualmente, Alejandro Chafuen, nascido em Buenos Aires, comanda o think tank, posto que ocupa desde 1991, três anos após a morte de Fisher (BAGGIO, 2016; FANG, 2016; MELO, 2017; ROCHA, 2017).

Consultando o site da Atlas Network, na aba "Partners" dentro de "Global Directory", deparase com a frase "Explore nosso extenso diretório de 482 parceiros em 92 países em todo o mundo. As forças de nossos dedicados parceiros criaram algumas das maiores melhorias do mundo em liberdade.", além de um mapa interativo onde é possível ver o número de organizações em cada continente. $\mathrm{Na}$ América Latina, por exemplo, existem 84. Ainda é possível filtrar por país. Sendo assim, por meio da filtragem, localizamos 12 parceiros da Atlas no Brasil ${ }^{14}$. São eles: Estudantes Pela Liberdade (Belo Horizonte, Brasil), Instituto De Estudos Empresariais (Porto Alegre, Brasil), Instituto De Formação De Líderes (Belo Horizonte, Brasil), Instituto Liberal (Rio De Janeiro, Brasil), Instituto Liberal De São Paulo (São Paulo, Brasil), Instituto Liberdade (Porto Alegre, Brasil), Instituto Ludwig Von Mises Brasil (Sao Paulo, Brasil), Instituto Millenium (Rio De Janeiro, Brasil), Líderes Do Amanhã Institute (Vitoria, Brasil), Mackenzie Center For Economic Freedom (Sao Paulo, Brasil) e Students For Liberty Brasil (São Paulo, Brasil).

Segundo o trabalho de Silva (2016, p. 71), o Movimento Brasil Livre constava nessa lista de parceiros da Atlas, no mesmo site, quando o autor a acessou em 22 de fevereiro de 2016. Baggio (2016, p. 7), que atestou o MBL na lista em maio de 2016, não o encontrou quando verificou de novo em julho de 2016.

\footnotetext{
13 "Fisher começou a levantar fundos junto a empresas com a ajuda de cartas de recomendação de Hayek, Thatcher e Friedman, instando os potenciais doadores a ajudarem a reproduzir o sucesso do IEA através da Atlas." (FANG, 2016)

$14 \quad$ Disponível em: <https://www.atlasnetwork.org/partners/global-directory/latin-america-andcaribbean/brazil $>$. Consulta realizada em 25/01/2018.
} 
Cadernos de Estudos Sociais e Políticos, Rio de Janeiro, vol. 6, 2018.

Notamos também o Estudantes pela Liberdade como parceira da Atlas. O think tank foi fundado por Fábio Ostermann, Juliano Torres e Anthony Ling (que é filho de Willian Ling, do Instituto de Estudos Empresariais), baseado no Students for Liberty, um grande think tank norteamericano.

Porque as conexões de membros do MBL com o EPL e a Atlas Network são importantes para este trabalho? Como vimos, a defesa do liberalismo econômico está presente em todas as organizações citadas, incluindo o MBL. Reagan e Thatcher, governantes lembrados por promoverem políticas públicas liberais na economia, são grandes influências para o Movimento, como podemos perceber no discurso de Flávio Rocha, citado na introdução deste artigo. Dessa forma, no próximo bloco, buscaremos refletir sobre o ativismo online do MBL através de vídeos do YouTube.

\section{O ATIVISMO DO MBL NO YOUTUBE}

Apresentaremos alguns resultados parciais de análise de amostra de 30 vídeos. O intervalo selecionado corresponde ao dia em que o primeiro vídeo foi postado no canal do MBL, 17 de outubro de 2014 até o dia 2 de abril de 2018.

Em relação à forma, os vídeos foram agrupados em três principais categorias, tendo em vista suas características: as montagens, os vídeos com cenas de protestos e as transmissões ao vivo.

O primeiro vídeo postado no canal do YouTube do MBL, no dia 17/10/2014, de título "Chico Buarque apoia Dilma 45"15, é do tipo montagem. O vídeo originalmente apresentado na campanha de Dilma Rousseff nas eleições, em que o cantor Chico Buarque demonstra seu apoio, é dublado com uma voz desconhecida, que diz:

\footnotetext{
Eu voto na Dilma porque dá dinheiro para os amigos, confio nela. Um robô sobretudo que não sabe completar uma frase, e que desmaia quando apanha no debate. Eu voto nela porque com ela eu tenho certeza que minhas verbas da lei Rouanet serão mantidas, aprimoradas, aprofundadas. Dilma, você compra o que a gente pensa, você rouba e a gente defende. Em 2010, eu voltei na Dilma porque eu sou uma putinha do Lula. Este ano voto na Dilma porque ela fode tua roda viva.
}

Após a fala de Chico Buarque, aparece o "Dilma presidente, vice Michel Temer", relativo ao vídeo original de campanha e logo depois, aparece o 45 bem grande na tela junto a 
Cadernos de Estudos Sociais e Políticos, Rio de Janeiro, vol. 6, 2018.

\#raioprivatizador abaixo. O locutor da campanha original fala "Dilma, presidenta", e então é cortado por outra voz, que diz “45”. O número 45 faz alusão ao PSDB, o mesmo de Aécio Neves na eleição à presidência da República de 2014.

Os vídeos que chamamos de montagens são caracterizados por vídeos oficiais de campanhas, em sua maioria do PT, editados com o fim de buscar a sátira, o "cômico", ou mesmo rebater um argumento. No caso acima, notamos ainda um linguajar chulo nos comentários sobre Chico, Lula e Dilma.

Já em sete vídeos, encontramos cenas de protestos políticos que o Movimento Brasil Livre participou. O vídeo postado no dia 09/12/2014 ${ }^{16}$ inicia com a frase "6 de dezembro São Paulo" e com o grito dos manifestantes: "a nossa bandeira jamais será vermelha”; além das imagens do protesto na rua ao fundo. E logo há o foco numa camiseta, onde se pode ler "organização": "Movimento Brasil Livre" e "Vem Pra Rua". Depois começam a serem mostradas imagens do ato, com foco em vários cartazes. Notamos muitos manifestantes vestidos com a camiseta da seleção brasileira de futebol e portando a bandeira nacional brasileira. E então começam a serem mostrados membros do MBL discursando.

Renan Santos, alternando com os outros membros do MBL, diz:

O governo da Dilma já não está acontecendo. Nunca antes nossos parlamentares de Brasília agiram da forma que eles estão agindo. Eles estão agindo com o coração, porque nós, no dia 1, no dia 15, o pessoal da Vem Pra Rua antes, nós obrigamos os nossos parlamentares a agirem como homens. Agora eles vão agir como homens. Haddad, em 2016 tua casa caiu filhão, caiu mesmo. Não vai rolar. A questão é, os políticos sempre pautaram a gente, de agora em diante, nós pautamos eles.

Logo, Kim Kataguiri diz: "nós nunca vamos deixar que este país seja uma ditadura totalitária, que é o objetivo do PT". Depois disso, ouvimos os manifestantes gritando: "Ei Haddad, tomamos a cidade"; Paulo Batista diz: "Fora PT, Fora PT! Vamos buzinar você que é contra o PT! Buzinaço, buzina aí!"; Alexandre Santos, discursa: "Nós ainda estamos aqui, e vamos continuar contra esses bandidos, salafrários, inimigos da liberdade.”. Por último, Paulo Martins diz:

Que isso dona Dilma, nós não aceitamos ver a Petrobrás estuprada na verdade, que é isso que acontece, temos uma quadrilha patrocinada pelo PT e seus aliados alugados, que usam toda a estrutura da empresa para financiar o seu maldito projeto de poder, para se beneficiar, e também para servir aos planos nefastos do foro de SP. O Brasil consegue furar a barreira na informação graças à liberdade na Internet que a tecnologia e o capitalismo nos proporcionou. 
Cadernos de Estudos Sociais e Políticos, Rio de Janeiro, vol. 6, 2018.

Notamos que, nos discursos, destacam-se as ideias de pautar o congresso por meio das ruas, de tirar o PT do poder e de defender a Internet como meio alternativo para a busca de informação.

O foco nas imagens dos cartazes é um recurso bastante utilizado nesse e em outros vídeos com cenas de protestos políticos. Nesse, podemos ler em cartazes: "Atlas revoltou-se contra o PLN36"17, "Fora Dilma, Pede pra Sair, Leve o PT", "Menos Marx Mais Mises”, "Menos Duvivier Mais Gentili1" ${ }^{18 ", ~ " M e n o s ~ K e y n e s, ~ M a i s ~ H a y e k ~}{ }^{19}$ ", "Olavo tem razão $0^{20 ",}$, "liberdade política" e "Dilma 171". Aqui percebemos a grande quantidade de referências que o estudo dos cartazes dos protestos podem nos fornecer. Nesse caso, notamos referências ao liberalismo econômico.

No dia 18 de março de 2015, foi postado um vídeo ${ }^{21}$ com o título "15 DE MARÇO - A maior manifestação da história do Brasil”. Ele começa com imagens do protesto a favor do impeachment de Dilma Rousseff, com o áudio do canto: “ôôô, o PT roubou”. São mostradas várias imagens do ato na Avenida Paulista, onde podemos observar grande concentração de pessoas, que estão vestindo em sua maioria camisetas verde e amarelo da seleção brasileira de futebol. Logo após, aparece a frase "A maior manifestação da história do Brasil". E começa o discurso de Fernando Holiday, que está em cima de um palanque:

O PT há anos vem dividindo a sociedade: nos dividiu entre ricos e pobres, nos dividiu entre negros e brancos. Mas a partir de hoje, suas divisões inúteis não vão mais separar o povo brasileiro. Porque estamos demonstrando, que somos um só povo, de uma só nação. Temos uma hoje uma presidente claramente envolvida em um lamaçal de corrupção.

”Nós queremos, pedimos, imploramos, Impeachment já!

E então, Renan Santos:

Para os parlamentares de oposição, o dinheiro deles está aqui 'ó', no bolso, durante 4 anos. Eles pediram para a Dilma sangrar e a gente sangrar junto. Vocês querem esperar? Vocês querem sangrar com a Dilma? Vocês querem mais três anos de mentiras? Vocês querem perder seus empregos? Então é impeachment já!

17 Referências ao livro "A revolta de Atlas", que alguns dizem ser a referência para o nome da Atlas Foundation, think tank que coordena uma rede com outros think tanks menos na América Latina, e que Kim Kataguiri é membro. Já o PL36/14 refere-se a um projeto de lei que altera o cálculo do superávit primário.

18 Uma referência aos humoristas Gregório Duvivier, que possui posicionamentos políticos ligados ao espectro ideológico de esquerda, e a Danilo Gentili, com posicionamentos à Direita.

19 Referência a John Maynard Keynes, que defendia a intervenção estatal na Economia, e a Friedrich Hayek, que defendia a ultra liberalização da Economia.

$20 \quad$ Conhecido conservador brasileiro, escritor do Best Seller: "O mínimo que você precisa saber para não ser um idiota".

21 Disponível em: <https://www.youtube.com/watch?v=qem_0OGZEjk>. 
Cadernos de Estudos Sociais e Políticos, Rio de Janeiro, vol. 6, 2018.

São mostradas imagens da manifestação, onde são focados alguns cartazes durante alguns segundos, com os letreiros “O PT É UM CANCER TOTALITÁRIO” e "MENOS ESTADO, MENOS IMPOSTO”. Notamos mais pessoas com bandeiras do Brasil e com camisetas da seleção brasileira de futebol.

Renan Santos faz a leitura da do que chama de "carta aos congressistas", que é repetida pelas pessoas na manifestação:

Nós os brasileiros, exigimos nessa tarde que abandonem seu discurso fácil e sintam as
vozes das ruas. Não aceitamos um governo golpista, que rouba nosso dinheiro, que rouba
nossa esperança, e acima de tudo, que rouba nossa liberdade. Não faremos sacrifícios,
nem pagaremos a conta, daqueles que insistem em nos oprimir. Caros congressistas. O
povo brasileiro exige apenas uma coisa. Deixem seus interesses de lado e sejam oposição.
Impeachment Já!

Depois disso, ocorre o discurso de Kim:

O PT diz que a gente é fascista, o PT diz que a gente é golpista. Mas os fascistas são eles, os golpistas são eles. Se impeachment é golpe, porque o PT pediu impeachment do Collor, porque pediu impeachment do FHC? Os golpistas são eles. Eles são a elite. O que Lula e Dilma fizeram não é só motivo para cassação não, é motivo pra cadeia. Eles só não foram presos até agora, porque a oposição de verdade não estava na rua, porque o povo não estava na rua. O PT pode mandar o MST, o PT pode mandar a CUT, mas ele nunca vai acabar com a maior oposição do Brasil, que é o povo brasileiro!

Após Kim, aparecem as seguintes frases em verde em amarelo: “A moderação na defesa da liberdade não é uma virtude.", ”Seja oposição!” e “12abr será ainda maior!".

Um dos conceitos muito utilizados nos estudos sobre mobilização política é o de frame, desenvolvido por Benford e Snow (1986; 2000), baseado na obra de Erving Goffman (1974).

Para Goffman, (1974, p.21 apud BENFORD e SNOW, 2000, p.614) os frames denotam "esquemas de interpretação" que permitem aos indivíduos "localizar, perceber, identificar e rotular" ocorrências dentro de seu espaço vital e do mundo em geral.

Frames de ação coletiva, derivados da ideia goffmaniana, são conjuntos de crenças e significados orientados para a ação que inspiram e legitimam as atividades e campanhas de uma organização do movimento social. Além disso, "desempenham uma função interpretativa simplificando e condensando aspectos do que está acontecendo, visando mobilizar apoiadores, angariar apoio de espectadores e desmobilizar antagonistas". (BENFORD e SNOW, 2000, p.614)

Os frames ou quadros de ação coletiva são gerados pelo trabalho de significação e construção de significado que visa simplificar aspectos da realidade para conseguir apoio e mobilizar pessoas, chamado de framing ou enquadramento. Recuperando o conceito de tarefas principais de enquadramento (BENFORD e SNOW, 2000), podemos pensar primeiramente no enquadramento diagnóstico, que diz respeito à identificação das fontes de causalidade, culpa e /ou agentes 
Cadernos de Estudos Sociais e Políticos, Rio de Janeiro, vol. 6, 2018.

culpáveis. Nos dois primeiros vídeos com cenas de protestos, um ocorrido no dia 06/12/14 e o outro em 15/03/15, vemos o PT, incluindo Dilma e Lula, que "roubou", que é corrupto, que dividiu a sociedade, como a principal causa de culpa do problema. Já no enquadramento prognóstico, que diz respeito à articulação de uma solução proposta para o problema, assim como as estratégias para executar o plano, vemos a defesa do Impeachment, que seria conseguida através do eco das "vozes das ruas" do "povo brasileiro", isto é, dos protestos de rua. No enquadramento motivacional, entendido como uma justificativa para o envolvimento na ação coletiva, incluindo a construção de vocabulários apropriados de motivação, podemos pensar no discurso de Renan Santos do dia 15/03: "Eles pediram para a Dilma sangrar e a gente sangrar junto. Vocês querem esperar? Vocês querem sangrar com a Dilma? Vocês querem mais três anos de mentiras? Vocês querem perder seus empregos? Então é impeachment já!”.

Claramente vemos vocabulários motivacionais que tentam mobilizar emoções, e que se unem no discurso ao enquadramento prognóstico, a defesa do impeachment.

As cenas dos protestos, dos cartazes erguidos pelos manifestantes, dos discursos dos membros do MBL, com a música ao fundo, mostram o desejo de transmitir as emoções de quem presenciou o fato. E, somadas a edição das imagens, direcionam a atenção do espectador do vídeo para uma compreensão "enquadrada" do fenômeno.

Dessa forma, o espectador sente-se convidado a apoiar o movimento tanto com um clique para "curtir" o vídeo, quanto para comparecer a novos atos nas nos espaços físicos das ruas, bem como no apoio financeiro realizado por meio de doações.

Tatagiba, Trindade E Teixeira (2015) podem nos ajudar a refletir sobre as cenas de protesto presentes nos vídeos acima. Em seu ensaio, "CorruPTos", buscam refletir sobre os "eventos de protestos à direita" de forma cronológica, que ocorreram em São Paulo desde o ano de 2007 até 2015. O texto situa o MBL como um integrante desses protestos, que se intensificaram no Brasil a partir de 2013, com as Jornadas de Junho; em 2014, com os períodos pré e pós-Eleições presidenciais; e atingiram o auge em 2015, com a manifestação do dia 15 de março.

Para os autores, três organizações vão se destacar, nos atos pré e pós-eleições em 2014: O Vem Pra Rua, o Movimento Brasil Livre e Revoltados Online. Os grupos "têm no antipetismo o grande traço em comum, ou seja, seu grande objetivo é tirar o PT do poder", porém "o discurso de livre mercado e da concorrência capitalista como projeto político parece ser defendido de forma mais explícita pelo MBL" (TATAGIBA; TRINDADE; TEIXEIRA, 2015, p. 16). 
Cadernos de Estudos Sociais e Políticos, Rio de Janeiro, vol. 6, 2018.

Segundo os autores, tanto o MBL quanto o Vem Pra Rua mostravam seu "apego à ordem democrática", rechaçando uma possível intervenção militar. Porém, o "Revoltados On-line 22 parece ter um discurso um tanto ambíguo nesse aspecto, pendendo mais para o lado do autoritarismo" (TATAGIBA;TRINDADE;TEIXEIRA, 2015, p. 16).

As mesmas organizações se destacaram na manifestação do dia 15 de março de 2015 (TATAGIBA; TRINDADE; TEIXEIRA, p. 18-19):

No dia 15 de março, após meses de articulação e de convocação pelas redes sociais, realiza-se em várias cidades do país uma manifestação de grandes proporções contra a Presidente Dilma e o governo do PT. Os organizadores principais continuam sendo o MBL, Vem Pra Rua e Revoltados On-line. Na época, estas três organizações concordavam com o alvo, o PT, mas o Vem pra Rua discordava da bandeira pelo impeachment. A cidade de São Paulo foi, sem dúvida, o grande epicentro da manifestação, com 1 milhão de pessoas ocupando a Avenida Paulista segundo os organizadores - o Instituto Datafolha estimou o público total em 210 mil. A despeito da divergência numérica, o Datafolha destacou que era a maior manifestação na Avenida Paulista desde as "Diretas Já" em 1984.

Os autores também utilizam o conceito de frame. Para eles, as justificativas dos protestos estão ancoradas em dois frames principais: o combate à corrupção e o antipetismo (TATAGIBA; TRINDADE; TEIXEIRA, 2015, p. 4). Notamos os dois nos discursos presentes nos vídeos.

Uma característica importante do ativismo online do MBL é a convivência com o espaço offline numa relação de continuidade. Isso é, a mesma manifestação de rua que ocorre em um espaço físico, também pode ser acompanhada por meio das mídias sociais. A instantaneidade da circulação de informação dentro de um ato comunicacional entre dois ou mais indivíduos fica evidente em alguns vídeos do MBL, que são transmitidos ao vivo através do YouTube, e após o fim da transmissão, ficam disponíveis para acesso em qualquer momento posterior. O "MBL NEWS", programa em que os membros do movimento comentam notícias, é um desses exemplos.

No dia 13/12/2017 é transmitido, ao vivo, o vídeo ${ }^{23}$ (com a maior duração de nossa amostra, 1 hora e 33 minutos) de título "MBL NEWS | 13/12/17 | PREVIDÊNCIA ADIADA, DESARMAMENTO SEGUE NO SENADO, E VD. MARISA LETÍCIA? WTF?”. Os apresentadores Salsicha (Alexandre Santos) e Eric Balbinus leem as notícias selecionadas de seus smartphones, assim como as comentam e fazem piadas entre as duas coisas. Salsicha explica que o

22 No dia 28 de agosto de 2016, a página do Facebook "Revoltados Online", com mais de 2 milhões de seguidores e mais de 100 mil postagens foi excluída por desrespeito às normas da plataforma. Em reportagem da Revista Piauí com Marcello Reis, criador da página, lemos: “A tréplica do Facebook foi direta: "Nossas regras proíbem conteúdos como discurso de ódio e homofobia."”. Disponível em: <http://piaui.folha.uol.com.br/o-ostracismo-domaior-revoltado-online/>.

23 Disponível em: <https://www.youtube.com/watch?v=i2LLjP9fE0U\&t=4297s $>$. 
Cadernos de Estudos Sociais e Políticos, Rio de Janeiro, vol. 6, 2018.

vídeo está sendo transmitido para ser melhor assistido pelo YouTube, e convoca as pessoas que estiverem vendo pelo Facebook a migrarem para a outra plataforma.

O programa busca a interação com seus espectadores e, ao mesmo tempo, a captação de recursos, por meio dos pimbas. Os pimbas são comentários enviados através do recurso superchat ${ }^{24}$ do Youtube, que devem ser lidos pelos apresentadores ao fim do programa. Esse tipo de comentário só possível através da "doação" de um valor. Se o valor for menor que 5 reais, serão apenas lidos; se forem iguais ou maiores que 5 reais, serão lidos e respondidos.

O superchat, representado pelo comentário destacado através do pagamento, é uma funcionalidade do Youtube disponível para qualquer transmissão ao vivo. O pimba é o nome que o MBL dá para essa funcionalidade, com o incremento da resposta ao comentário. Uma das outras funções do pimba é a quebra do roteiro do programa, possibilitando o apoio dos espectadores também para escolher a pauta a ser discutida mediante o pagamento.

O locutor do MBL NEWS diz durante o vídeo:

Tem gente perguntando como faz pimba, como doa para o programa. Os pimbas são os superchats, você faz uma doação e você faz uma pergunta também, ou se quiser fazer uma piada, ou se quiser mandar a gente tomar no... é só doar pelo superchat.

No início deste vídeo, foi anunciado que a pessoa por trás da maior "doação", ou do maior "pimba", ganharia dois livros: Quem é esse moleque para estar na Folha?, de Kim Kataguiri, e Por que o Brasil é um país atrasado?, de Luiz Philippe Órleans e Bragança, descendente da família imperial brasileira, que Salsicha chama de "príncipe".

Como explicamos, o vídeo acima foi transmitido ao vivo pelo YouTube. Temos três vídeos do tipo em nossa amostra. Eles apresentam algumas características em comum, tais como as interações com os espectadores através dos pimbas; a duração grande dos vídeos em relação ao resto da amostra, com média de uma hora; o formato e cenário dos programas, que lembram programas jornalísticos televisivos.

\footnotetext{
$24 \quad$ "O Super Chaté uma nova maneira para fãs e criadores de conteúdo interagirem durante transmissões ao vivo. Os fãs podem comprar Super Chats para destacarem mensagens dentro do stream de bate-papo ao vivo. Os Super Chats se destacam entre as outras mensagens de duas formas: Seu Super Chat é destacado com uma cor diferente; seu Super Chat é fixado no painel de mensagens por um período determinado, dependendo do valor selecionado. A cor do seu Super Chat, o período em que ele fica fixado no painel e o comprimento máximo da mensagem são determinados pelo valor da sua compra.”. Disponível em: < https://support.google.com/youtube/answer/7277005?hl=pt-BR>.
} 
Cadernos de Estudos Sociais e Políticos, Rio de Janeiro, vol. 6, 2018.

\section{CONSIDERAÇÕES FINAIS}

O objetivo do presente trabalho era analisar o surgimento do Movimento Brasil Livre assim como sua forma de atuação. A rede de think tanks que o movimento faz parte, com objetivos bem delineados, e com diversos recursos à disposição são fundamentais para o entendermos. O estudo dessas relações com instituições antigas e estabilizadas mostram que o MBL não começou sozinho, de forma espontânea, mas foi auxiliado por profissionais. Porém, a dimensão do intenso ativismo é a diferença: o MBL não é um think tank. Ele não deixa de tentar influenciar o debate público, mas o faz por meio de ações políticas mais diretas, utilizando-se de passeatas, carreatas, mídias sociais e mesmo da entrada na carreira política institucional.

O modo como o movimento utilizou o YouTube no contato com potenciais apoiadores de suas pautas e na arrecadação de recursos é outra contribuição. Acreditamos que a mídia social é fundamental para o Movimento difundir seus frames ou quadros e, assim, disputar os significados de diversos eventos com fins de mobilizar apoiadores e recursos.

\section{REFERÊNCIAS}

AMARAL, Marina. A nova roupa da direita. Agência Pública, 2015. Disponível em: https://apublica.org/2015/06/a-nova-roupa-da-direita/. Acesso em 15/01/2018

BAGGIO, Kátia Gerab. Conexões ultraliberais nas Américas: o think tank norte-americano Atlas Network e suas vinculações com organizações latino-americanas. Encontro Internacional Da Associação De Pesquisadores E Professores De História Das Américas, v. 12, 2016. Disponível em: $<$ http://ifg.edu.br/attachments/article/7536/Conex $\%$ C3\%B5es $\% 20$ ultraliberais $\% 20$ nas $\% 20 \mathrm{Am}$ $\% \mathrm{C} 3 \%$ A 9 ricas $\% 20 \mathrm{o} \% 20$ think $\% 20$ tank $\% 20$ norte-

americano $\% 20$ Atlas $\% 20$ Network $\% 20 \mathrm{e} \% 20$ suas $\% 20$ vincula $\%$ C3 $\%$ A $7 \%$ C3 $\%$ B 5 es $\% 20$ com $\% 20$ or ganiza $\% \mathrm{C} 3 \% \mathrm{~A} 7 \% \mathrm{C} 3 \% \mathrm{~B} 5 \mathrm{es} \% 201$ atino-

americanas $\% 20 \% \mathrm{E} 2 \% 80 \% 93 \% 20 \mathrm{~K} \% \mathrm{C} 3 \%$ A1tia\%20Baggio.pdf>. Acesso em 20/12/2017

BENFORD, Robert D.; SNOW, David A. Framing processes and social movements: An overview and assessment. Annual review of sociology, v. 26, n. 1, p. 611-639, 2000

CARDOSO, Bruno. Por que fazer uma sociologia da internet? Sobre o caso Cambridge Analytica e Facebook. Blog do Laboratório de Estudos Digitais - IFCS/UFRJ. Disponível em: 
Cadernos de Estudos Sociais e Políticos, Rio de Janeiro, vol. 6, 2018.

<https://ledufrj.wixsite.com/ledufrj/single-post/2018/03/25/Por-que-fazer-uma-sociologia-dainternet-Sobre-o-caso-Cambridge-Analytica-e-Facebook>. Acesso em 01/05/2018

FANG, Lee. Esferas de influência: como os libertários americanos estão reinventando a política latino-americana. The Intercept Brasil, 2017. Disponível em: $<$ https://theintercept.com/2017/08/11/esfera-de-influencia-como-os-libertarios-americanosestao-reinventando-a-politica-latino-americana/ >. Acesso em 01/05/2018

GROS, Denise Barbosa. Considerações sobre o neoliberalismo como movimento ideológico internacional. Ensaios FEE, v. 29, n. 2, p. 565-590, 2008

MITCHELL, Timothy. Rethinking economy. Geoforum, v. 39, n. 3, p. 1116-1121, 2008

MITCHELL, T. How Neoliberalism makes its world. In: Mirowski, P., \& Plehwe, D. (2015).The Road from Mont Pèlerin: The Making of the Neoliberal Thought Collective. (Vol. 16)

ROCHA, C. O papel dos think tanks pró-mercado na difusão do neoliberalismo no Brasil. Millcayac - Revista Digital de Ciencias Sociales, v. 4, n. 7, p. 95-120, 28 set. 2017. Disponível em: $<$ http://revistas.uncu.edu.ar/ojs/index.php/millca-digital/article/view/1020>. Acesso em $01 / 05 / 2018$

SILVA, Danniel Gobbi Fraga da. Identidade em ambiente virtual: uma análise da rede estudantes pela liberdade. Dissertação (Mestrado em Ciência Política). Instituto de Ciência Política, Universidade de Brasília, 2016

SNOW, D. et al. Frame alignment processes, micromobilization, and movement participation. American sociological review, p. 464-481, 1986.

TATAGIBA, Luciana; TRINDADE, Thiago; TEIXEIRA, Ana Claudia Chaves. CorruPTos. Um ensaio sobre protestos à direita no Brasil (2007-2015). no prelo:[sn], 2015 